\title{
Capsule Commentary on Behar et al., Acceptability of Naloxone Co-Prescription Among Primary Care Providers Treating Patients on Long-Term Opioid Therapy for Pain
}

\author{
William Cheung, MD
}

Zablocki VAMC, Milwaukee, WI, USA

J Gen Intern Med 32(3):313

DOI: $10.1007 / \mathrm{s} 11606-016-3947-0$

() Society of General Internal Medicine 2016

$\mathrm{D}$ ue to the alarming number of opiate-related deaths, the Centers for Disease Control and Prevention (CDC) guidelines for preventing overdose deaths include expanding access to and use of naloxone. ${ }^{1}$ In this cross-sectional study, Behar et al. examined the views of primary care providers regarding the acceptability of co-prescribing naloxone and opioids. $^{2}$ San Francisco safety-net primary care providers were surveyed 4-11 months after their clinic had begun offering naloxone and had received naloxone training. Providers who had practiced medicine for $>5$ years or who had a larger panel of opioid-using patients tended to prescribe naloxone more often. Most prescribers ( $>99 \%$ ) reported a willingness to prescribe naloxone, particularly for high-risk individuals, but felt that prescribing naloxone consumed too much time, that the naloxone device was too complex, that support for patient education was lacking or that insurance coverage was limited.

The results of the study should be interpreted cautiously. Most importantly, this study surveyed providers after a clinicwide effort to train and encourage increased naloxone prescribing. Thus the survey responses may not reflect the attitudes of providers who have not received training in naloxone use. Second, survey data is not always a good approximation of behavior. From this intervention in this setting, these authors demonstrated that $38 \%$ of patients receiving opiates were given naloxone. ${ }^{3}$ It would have been helpful to assess whether there was a correlation between respondent survey attitudes and prescribing behavior. Self-reported data may not be reliable, due to social desirability bias. While anonymous surveys minimize social desirability bias, these surveys also diminish the accuracy of self-reported data. ${ }^{4}$ Furthermore, nearly onethird of the surveys were not completed. This introduces non- responder bias from incomplete surveys that can over- or underestimate measured variables.

Within the context of an ongoing epidemic of opioid overdose and deaths, this study reveals that naloxone prescribing can be more common, and even "reflexive", with appropriate training. From a practical perspective, prescribing naloxone may help in initiating more detailed discussion with patients about drug and opiate safety. There still exist barriers that limit the feasibility of naloxone prescribing, namely provider training and medication education. Patient-centered medical home clinic models may be better suited for overcoming these barriers. $^{5}$

Corresponding Author: William Cheung, MD; Zablocki VAMC, Milwaukee, WI, USA (e-mail: william.cheung@va.gov).

\section{Compliance with Ethical Standards:}

Conflict of Interest: The author has no conflict of interest with this article.

\section{REFERENCES}

1. Dowell D, Haegerich TM, Chou R. CDC guideline for prescribing opioids for chronic pain-United States, 2016. MMWR Recomm Rep. 2016;65(No. RR-1):1-49. doi: 10.15585/mmwr.rr6501el.

2. Behar E, Rowe C, Santos GM, Coffa D, Turner C, Santos NC, Coffin PO Acceptability of naloxone co-prescription among primary care providers treating patients on long-term opioid therapy for pain. J Gen Intern Med. 2016. doi:10.1007/s11606-016-3911-z.

3. Coffin PO, Behar E, Rowe C, Santos GM, Coffa D, Bald M, Vittinghoff E Nonrandomized intervention study of naloxone coprescription for primary care patients receiving long-term opioid therapy for pain. Ann Intern Med. 165(4):245-252.

4. Lelkes Y, Krosnick JA, Marx DM, Judd CM, Park B. Complete anonymity compromises the accuracy of self-reports. J Exp Soc Psychol. 2012;48(11):1291-9. doi:10.1016/j.jesp.2012.07.002.

5. Berdine H, Dougherty T, Ference J, et al. The Pharmacists' Role in the Patient-Centered Medical Home (PCMH): a white paper created by the Health Policy Committee of the Pennsylvania Pharmacists Association (PPA). Ann Pharmacother. 2012;46(5):723-50. doi:10.1345/aph.1R189. 